\title{
Halitosis de origen periodontal: revisión
}

\author{
MENÉNDEZ COLLA M* \\ NOGUEROL RODRÍGUEZ B** \\ CUESTA FRECHOSO $\mathrm{S} * * *$ \\ GALLEGO PÉREZ M*** \\ TEJERINA LOBO JM ${ }^{\mathrm{a} * * * *}$ \\ SICILIA FELECHOSA $\mathrm{A} * * * * *$
}

\begin{abstract}
Menéndez Collar M, Noguerol Rodríguez B, Cuesta Frechoso S, Gallego Pérez M, Tejerina Lobo $\mathrm{JM}^{\mathrm{a}}$, Sicilia Felechosa A. Halitosis de origen periodontal: revisión. Av Periodon Implantol. 2004; 16, 1: 19-33.
\end{abstract}

\begin{abstract}
RESUMEN
El mal aliento, mal olor de boca o halitosis, son términos que se utilizan para describir un olor ofensivo que emana de la cavidad oral, independientemente de que las sustancias de olor desagradable provengan de fuentes orales o no orales. La mayoría de las halitosis se originan en el interior de la boca. Se han atribuido principalmente a compuestos volátiles sulfurados (CVSs) tales como sulfídrico, metil mercaptano y dimetil sulfuro. La causa primaria es la existencia de bacterias gramnegativas, que son similares a las que causan las enfermedades periodontales. Estas bacterias producen CVSs a partir del metabolismo de distintas células epiteliales, leucocitos etc, localizadas en la saliva y en la placa dental principalmente. La superficie lingual esta cubierta de una gran cantidad de células epiteliales descamadas y bacterias, que pueden, a traves de su actividad proteolítica y capacidad de putrefación, producir CVSs.

El objetivo de este artículo de revisión es: $1^{\circ}$ ) analizar la importancia de la halitosis oral en el contexto actual, $2^{\circ}$ ) estudiar los datos sobre su etiología y $3^{\circ}$ ) valorar la evidencia de la asociación entre las enfermedades periodontales y la halitosis de origen oral.
\end{abstract}

\section{PALABRAS CLAVE}

Halitosis oral, compuestos volátiles sulfurados, bacterias anaerobias, enfermedades periodontales, halitosis/etiología, cubrimiento lingual.

Aceptado para publicación: Julio 2003

\section{INTRODUCCIÓN}

El mal aliento, mal olor de boca o halitosis, son términos que se utilizan para describir un olor ofensivo que emana de la cavidad oral, independientemente de que las sustancias de olor desagradable provengan de fuentes orales o no orales, tales como vías respiratorias o aparato digestivo (1).

Este problema ha sido ignorado durante mucho tiem- po por los periodoncistas, aun siendo la microbiota subgingival y el cubrimiento lingual las fuentes de halitosis más frecuentes (2).

Desde hace cientos de años se ha recogido en la literatura el problema de la halitosis. De forma extensa se discute en el Talmud, libro litúrgico de los judíos, este problema. En él se refleja que si un hombre se casa con una mujer y posteriormente descubre que le huele el aliento, puede separarse sin cumplir los tér-

\footnotetext{
* Profesor invitado del Master de Periodontología. Universidad de Oviedo. Práctica Privada con dedicación exclusiva a Periodoncia e Implantes dentales en Córdoba.

** Profesor Asociado. Unidad Docente Odontología Integrada de Adultos. Universidad de Granada. Práctica Privada con dedicación exclusiva a Periodoncia e Implantes dentales en Granada.

*** Colaborador de Honor. Sección de Periodoncia. Universidad de Oviedo.

**** Profesor Titular de Periodoncia. Universidad de Oviedo. Práctica Privada con dedicación exclusiva a Periodoncia e Implantes dentales en Gijón.

***** Profesor Titular de Periodoncia. Universidad de Oviedo. Práctica Privada con dedicación exclusiva a Periodoncia e Implantes dentales en Oviedo.
} 
minos del contrato de matrimonio. De igual forma ha quedado reflejada, la importancia de la halitosis, en la civilización romana y en la griega a través de los escritores clásicos. El Islam también hace incapíe en la necesidad de un aliento fresco en el contexto de la higiene oral (1).

La literatura moderna sobre el mal aliento, data del siglo XIX, en el cual se escribió una monografía publicada por Howe en 1898. La investigación experimental con sujetos se inicia entre los años 1940 y 1950.

En los años 70, el mal aliento es asociado con la presencia de compuestos volátiles sulfurados (CVSs), principalmente el sulfídrico $\left(\mathrm{H}_{2} \mathrm{~S}\right)$ y el metilmercaptano $\left(\mathrm{CH}_{3} \mathrm{SH}\right)(3,4)$.

Hay evidencias que avalan el hecho de que la intensidad de halitosis oral esté asociada a un aumento de los niveles de CVSs intraorales (5, 6). En el interior de las bolsas periodontales existe un medio ambiente ideal para la producción de estos compuestos por parte de las bacterias periodontopatógenas.

El objetivo de este trabajo es $1^{\circ}$ ) analizar la importancia de la halitosis oral en el contexto actual, $2^{\circ}$ ) estudiar los datos sobre su etiología y $3^{\circ}$ ) valorar la evidencia de la asociación entre las enfermedades periodontales y la halitosis de origen oral.

\section{MÉTODOS E INSTRUMENTOS EMPLEADOS PARA EL DIAGNÓSTICO DE LA HALITOSIS}

Uno de los principales retos a los que se enfreta el estudio de la halitosis es el diagnóstico. Existen distintos métodos para valorar la halitosis. Se utilizan métodos de valoración cuantitativa y cualitativa. El método más utilizado para valorar la halitosis ha sido el análisis organoléptico (5-10). La elección de este método se basa fundamentalmente en que no requiere de instrumentación para llevarse a cabo, en que está al alcance de todos los profesionales y, principalmente, en que no existen técnicas e instrumentos alternativos que puedan sustituir, con eficacia, a está técnica.

Uno de los primeros trabajos, que permitió establecer la relación entre la halitosis y la presencia de CVSs en el aire de la cavidad oral fue realizado por Tonzetich, mediante cromatografía de gases con un detector fotométrico de llama (3). Otros grupos de investigación han seguido trabajando en este campo (11-13).

Más recientemente se han determinando cuantitativa y cualitativamente la presencia de CVSs en muestras de saliva y de superficie lingual mediante cromatografía

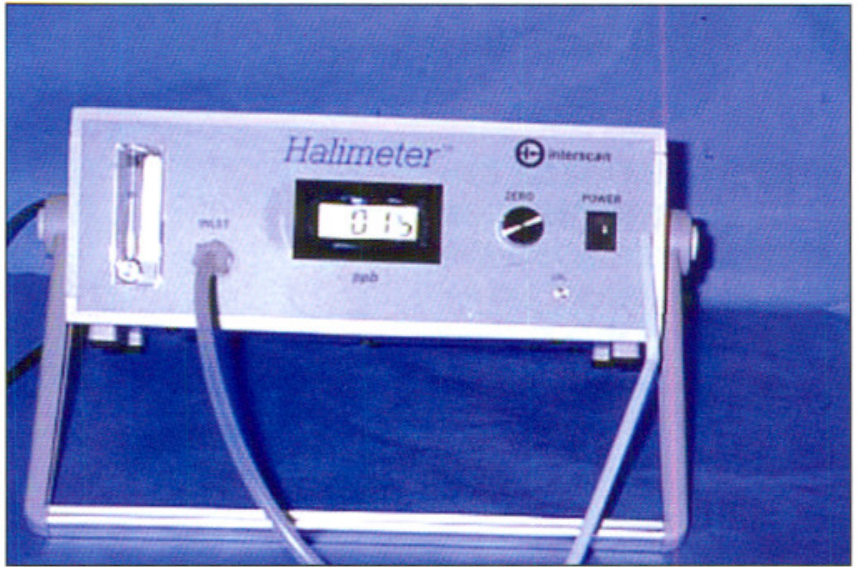

Fig. 1. Halimeter.

de gases basada en la detección por captura electrónica (14). En este estudio se identificaron 85 compuestos orgánicos volátiles, de los cuales 14 eran CVSs.

Las técnicas de microbiología anaeróbica introducidas en los años 80 han permitido la identificación y cuantificación de bacterias anaeróbicas relacionadas con CVSs (15-18).

La correlación observada entre los niveles de cadaverina en saliva y la presencia de CVSs en la halitosis (19) ha abierto la posibilidad de realizar cuantificaciones de esta diamina para determinar el grado de la halitosis.

El patrón de referencia que hoy se utiliza para la validación de nuevos instrumentos es la cromatografía de gases, pero no puede ser utilizado por el clínico en su consulta debido a su coste. De ahí que se haya trabajado en el desarrollo de nuevos métodos que puedan sustituir eficazmente a éste en la clínica.

En los últimos años han ido apareciendo distintos instrumentos que permiten valorar la presencia de CVSs con vistas a ser empleados por el clínico.

Uno de esto instrumentos es el Halimeter. Se trata de un equipo basado en medidas electroquímicas $(5,6)$. Este instrumento solo detecta el $100 \%$ de $\mathrm{H}_{2} \mathrm{~S}$, el $50 \%$ de $\mathrm{CH}_{3} \mathrm{SH}$ y dimetil disulfuro $\left(\mathrm{CH}_{3} \mathrm{~S} \mathrm{CH}_{3}\right)$ (Figura 1).

Otro instrumento desarrollado para detectar CVSs, es el BB Cheker (21). Está basado en las propiedades reductoras de los CVSs.

Recientemente se ha desarrollado la Diamond Probe,/Perio 2000, System. Este instrumento consiste en una unidad de lectura que tiene como periférico una sonda periodontal Michigan "0", está basado en tecnología electroquímica y permite detectar básicamente $\mathrm{H}_{2} \mathrm{~S}$ y $\mathrm{CH}_{3} \mathrm{SH}$ en el interior de las bolsas periodontales (Figura 2). 


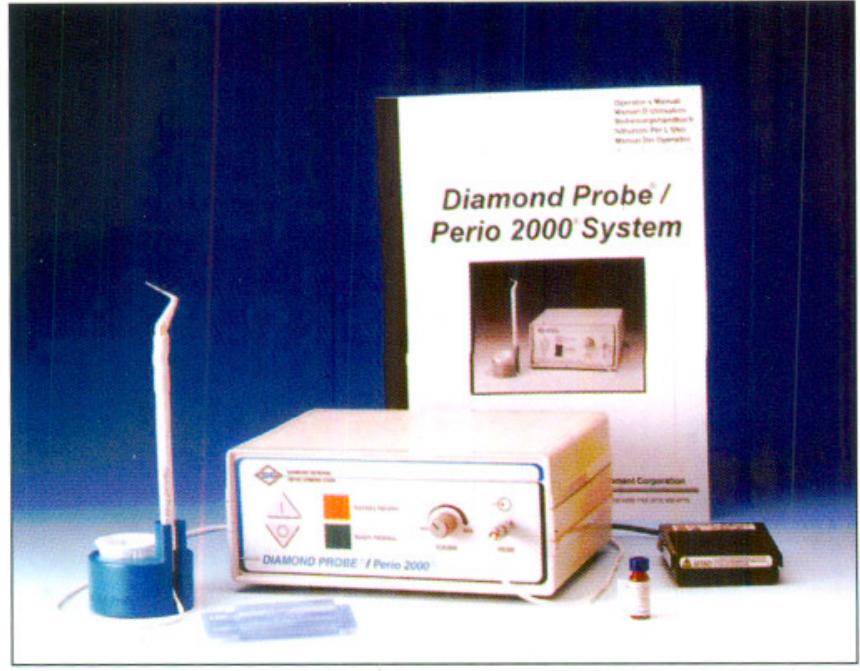

Fig. 2. Probe/Perio 2000 System.

\section{EPIDEMIOLOGÍA}

Los datos acerca de la epidemiología de la halitosis son escasos. Existen pocos estudios epidemiológicos e inconsistentes metodológicamente por lo que es dificil, a la luz de la evidencia científica actual, hablar sobre prevalencia y distribución de la halitosis oral.

Además, no existe un acuerdo unánime de la comunidad científica, ni un criterio estandarizado, para definir qué es halitosis (20), ni mediante procedimientos subjetivos $(5-8 ; 10)$, ni mediante procedimientos objetivos $(3,5,6,9,13,14,21,22)$. No obstante, contamos con datos que nos permiten hacernos una idea aproximada de la magnitud del problema.

En una muestra de 2.672 pacientes, con edades comprendidas entre 18 y 64 años y seleccionada de la población general en una Prefectura de Japón, se observó que entre el 6 y el $23 \%$ de los pacientes emitían, en algún momento del día, niveles superiores a las $75 \mathrm{ppb}$ de CVSs en el aire espirado por la boca. Estos registros fueron medidos con un Halimeter, y este parámetro fue considerado la medida del umbral social de la halitosis (23).

En un trabajo realizado en EEUU por Loesche, un $24 \%$ de las personas mayores de 60 años de edad contestaron afirmativamente que alguna vez les habían dicho que les olía mal el aliento. Este porcentaje se incrementaba hasta el $43 \%$, cuando se les preguntaba si ellos creían que alguna vez les había olido la boca.

Se ha estimado que más del $50 \%$ de la población de Norteamérica sufren de halitosis y el gasto anual en colutorios, spray y productos relacionados con el manejo de este problema está alrededor de 500 millones de dólares (24).

\section{CLASIFICACIÓN}

La halitosis no es una entidad nosológica per sé. Es un signo de la existencia de una entidad clínica. Existe una gran variedad de enfermedades que en su semiología incluyen la halitosis. No obstante, la clasificación de la halitosis la podemos establecer en función de su etiología. Al clasificar la halitosis es importante distinguir entre halitosis genuina, pseudohalitosis y halitofobia. $(20,25,26,27)$.

La halitosis genuina, a su vez, la podemos clasificar en fisiológica y patológica, pudiendo, además, ser de origen oral o extraoral. La halitosis fisiológica es de origen oral, está relacionada con el cubrimiento de la superficie dorsal de la lengua, es transitoria, se resuelve con medidas de higiene oral y no suele alterar la vida del que la padece. Un ejemplo de ella es la halitosis matutina (Figura 3 ).

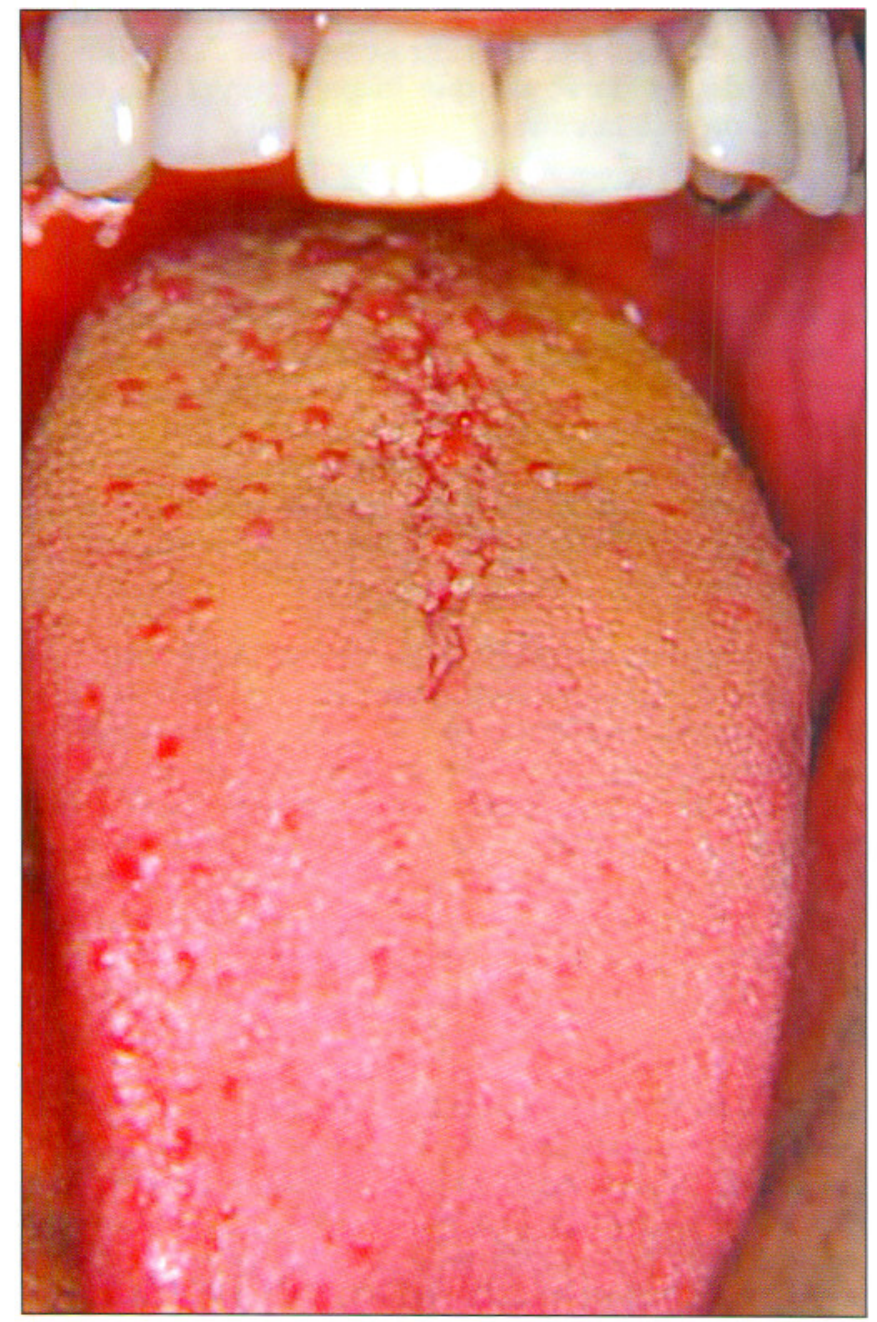

Fig. 3. El cubrimiento lingual. 


\section{TABLA 1.- CLASIFICACIÓN DE HALITOSIS CON SUS CORRESPONDIENTES NECESIDADES DE TRATAMIENTO}

\begin{tabular}{|l|l|}
\hline \multicolumn{1}{|c|}{ Clasificación } & Necesidades de tratamiento \\
\hline I. Halitosis objetiva & TN-1 \\
\hline I.A. Halitosis Fisiológica & \\
\hline I.B. Halitosis Patológica & \\
\hline I.B. 1. Causa oral & TN-1 y TN-2 \\
\hline I.B. 2. Causa extraoral & TN-1 y TN-3 \\
\hline II. Pseudohalitosis & TN-1 y TN-4 \\
\hline III. Halitofobia & TN-1 y TN-5 \\
\hline $\begin{array}{l}\text { Tomado de Sanz M, Roldan S, Herrera D. Fundamentals of breath } \\
\text { Malodour.J Comtemp Dent Pract 2001 Nov; (2) 4:001-017 }\end{array}$ \\
\hline
\end{tabular}

La halitosis patológica puede ser de causa extraoral e intraoral. Es crónica, no se resuelve con la higiene oral, aunque se puede enmascarar durante breves periodos de tiempo, interfiere de forma dramática en la vida de las personas que la padecen si son conscientes de que la sufren.

La halitosis de origen oral representa el $87 \%$ de las causas de halitosis $(1,20,25,28)$.

La halitosis extraoral se puede originar en distintos aparatos u órganos de la economía. Tomás en una reciente revisión (29) expone que la halitosis extraoral, puede tener su origen en estructuras otorrinolaringológicas, aparato digestivo, aparato respiratorio, hígado, riñón, enfermedades metabólicas y también pude deberse a alteraciones neuropsiquiatrícas.

Estudios realizados en Bélgica (28) en los que se utilizó el test de carbono 13, para detectar el Helycobacter pylori, bacteria relacionada con lesiones gastrointestinales y halitosis $(30,31)$, pusieron en evidencia que los problemas de halitosis por causa gastrointestinal son poco frecuentes. Solamente 20 pacientes de los 260 estudiados referían problemas gástricos, de los cuales únicamente a tres se les detecta la presencia de esta bacteria que, una vez eliminada mediante el tratamiento adecuado, no elimina la halitosis inicial en dichos.

En el aparato respiratorio, amigdalitis, faringitis, infecciones bronquiales o pulmonares, cuerpo extraños alojados en la nariz y sinusitis pueden dar lugar a halitosis. Aunque los otorrinolaringólogos atribuyen a las amigdalitis un importante papel en la etiología de la halitosis, diferentes estudios reflejan que dicho papel se reduce al $5 \%$ y el $8 \%(28,32)$.

\begin{tabular}{|l|l|}
\hline \multicolumn{2}{|c|}{ TABLA 2.- NECESIDADES DE } \\
TRATAMIENTO DE LA HALITOSIS
\end{tabular}

La pseudohalitosis o halitosis subjetiva ha sido descrita por la Sociedad Japonesa de Odontología (25) como una halitosis percibida por el paciente en la que no aparecen signos clínicos de halitosis real que pueda ser objetivable por medios organolépticos y/o físicos. Representa el $5 \%$ de los casos de consulta por halitosis y afecta más a mujeres $(80 \%)$ que a hombres $(20 \%)$, con mayor prevalencia en jóvenes (28). Tras un tratamiento exitoso de una halitosis objetiva o subjetiva, en el que no hay evidencia objetivable de halitosis y el paciente se sigue quejando de que le huele la boca el diagnóstico es de halitofobia. El tratamiento depende del psicólogo y/o psiquiatra.

Yaegaki y colaboradores, han desarrollado una clasificación (Tabla 1) en la que incluyen necesidades de tratamiento en función del diagnóstico alcanzado (Tabla 2).

\section{ETIOLOGÍA DE LA HALITOSIS ORAL}

La mayor parte de las halitosis tienen su origen en factores bucales locales que producen un elevado metabolismo microbiano en un medio alcalino, lo que origina la emisión de moléculas volátiles responsables del mal olor. $\mathrm{El} \mathrm{CH}_{3} \mathrm{SH}$ y $\mathrm{H}_{2} \mathrm{~S}$, han sido identificados como los CVSs más influyen en el mal aliento $(3,4,32,33)$.

Por otra parte, otros autores como Tangerman, afirman que $\mathrm{CH}_{3} \mathrm{SCH}$ y $\mathrm{H}_{2} \mathrm{~S}$ no son detectables en sujetos con cirrosis hepática que sufren halitosis, ni tampoco en sujetos sin halitosis y sanos $(12,13)$. En este caso, probablemente las moléculas implicadas en el mal olor de este tipo de pacientes no sean estos dos CVSs. Se 
han identificado al menos 85 moléculas distintas en una muestra de halitosis (14). Según Willis, existe una correlación negativa entre la intensidad de la halitosis en pacientes sin EP, caries o cubrimiento lingual, y el número de bacterias reductoras de sulfuro que producen $\mathrm{H}_{2} \mathrm{~S}$ (34). De todas formas, este autor llega a dicha conclusión porque entre sus resultados no encuentra una correlación etadísticamente significativa entre los dos métodos de diagnóstico utilizados, Halimeter y detección organoléptica. No obstante, el método estadístico utilizado para evaluar la concordancia entre los dos test de diagnóstico fue el coeficiente de correlación de Pearson y este no es el método apropiado para tal fin (35).

Estos CVSs proceden, en su mayoría, de la degradación de los aminoácidos ricos en azufre, hidrolizados por las bacterias gramnegativas en un medio alcalino. Esta degradación de proteínas por parte de las bacterias orales se asocia a la emisión mal aliento (Figura 4).

Desde los trabajos iniciales realizados por Tonzetich con cromatografía de gases (3), se acepta que los CVSs son los elementos fundamentales de la halitosis oral.

En trabajos realizados por Richter y Tonizetich (36), dividieron los compuestos volátiles producidos por la degradación de los aminoácidos en tres fracciones: ácidos, básicos y neutros. Observaron que los CVSs que generan mal olor están contenidos en la fracción ácida, y entre ellos se incluyen $\mathrm{H}_{2} \mathrm{~S}, \mathrm{CH}_{3} \mathrm{SH}$ $\mathrm{y}$, en mucha menor cantidad, $\mathrm{CH}_{3} \mathrm{SCH}_{3}$. Estas moléculas volátiles olorosas son liberadas por aminoácidos que contienen sulfuro, entre los que se incluyen la cisteina, la metionina y, en menor cantidad, el glutation oxidado y algunas peptonas. Otras moléculas volátiles como ácidos orgánicos, amonio y diaminas, producidos en el curso del metabolismo bacteriano, pueden también estar relacionadas, funcionando probablemente como modificadores del efecto en la producción de estos compuestos.

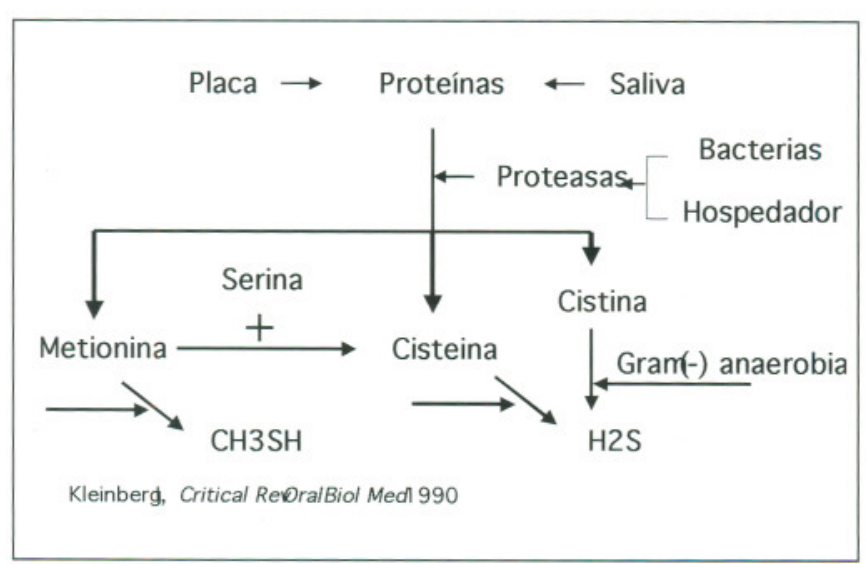

Fig. 4. Posible vía de generación de CVSs.

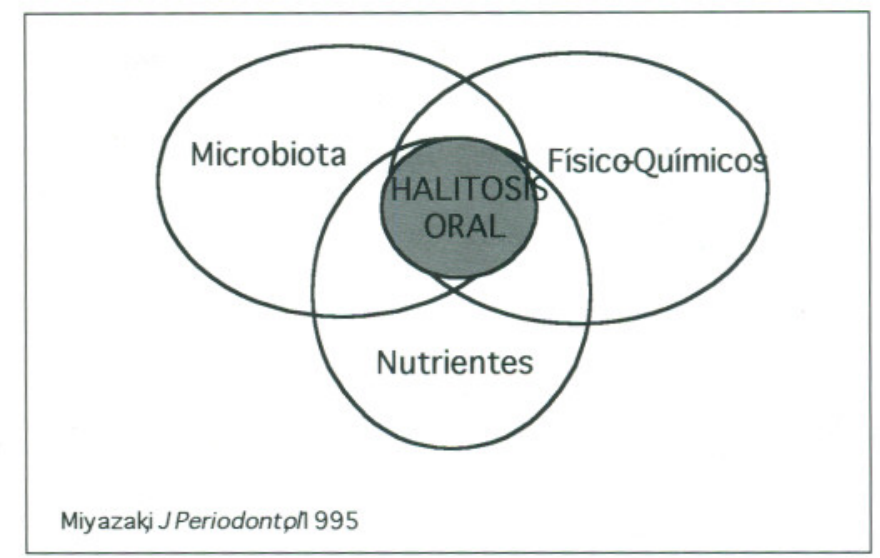

Fig. 5. Esquema de participación de los distintos factores implicados en la halitosis.

En otros trabajos recientes, (19) se ha puesto de manifiesto que la cadaverina y otras diaminas similares pueden ser también un componente importante en el origen de la halitosis. Estos investigadores han encontrado una correlación significativa entre los niveles de cadaverina detectados en saliva y niveles altos de halitosis, sin embargo, no encontraron ninguna relación entre halitosis y putresceina. Estos datos sugieren la posibilidad de que la síntesis de cadaverina en la cavidad oral se realize independiente de la producción CVSs y que ambos factores puedan contribuir a la halitosis oral, datos que avalan parcialmente las teorías de Willis y Tangerman $(12,13,34)$ que exponen que, en la halitosis oral, existen otras moléculas involucradas en lugar de $\mathrm{CH}_{3} \mathrm{SH}$ y $\mathrm{H}_{2} \mathrm{~S}$.

Como hemos expuesto anteriormente, para la producción de estas sustancias odoríficas se requiere la participación de la microbiota oral y de una serie de factores entre los que debemos destacar los fisicoquímicos y los nutricionales (Figura 5).

\section{FACTORES MICROBIANOS}

Las bacterias anaerobias gramnegativas han sido identificadas como el componente principal en la producción de halitosis $(32,33)$. Persson (16), utilizando cromatografía de gases realizó un experimento in vitro demostrando que las bacterias gramnegativas anaerobias que se encuentran en las bolsas periodontales son capaces de producir en suero humano $\mathrm{H}_{2} \mathrm{~S}$ y $\mathrm{CH}_{3} \mathrm{SH}$.

Este trabajo confirma la relación comunicada por Solis-Gaffar y cols. (22) entre la presencia de determinadas bacterias y la emisión de CVSs, identificando a las especies bacterianas Bacteroides melaninogenicus, Veillonella alcalescens, Fuso-bacterium 


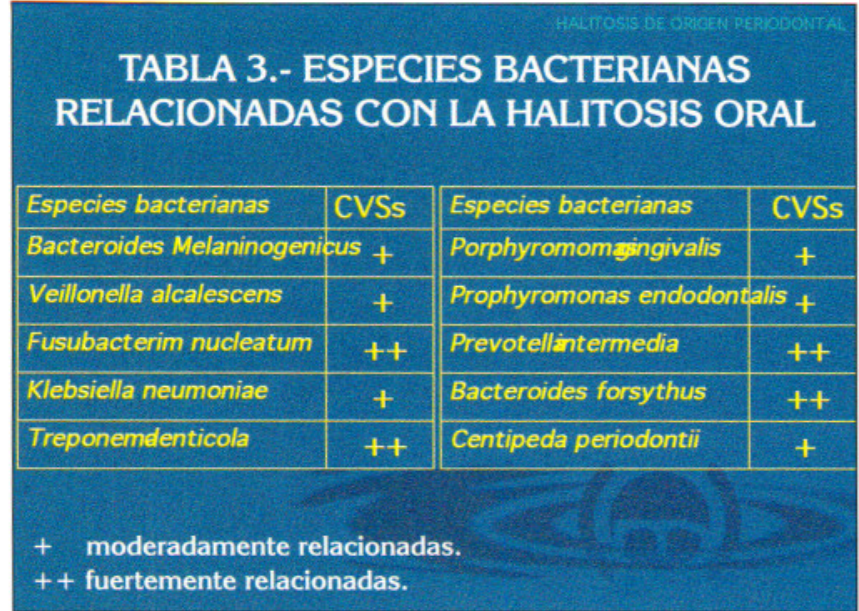

nucleatum y Klebsiella neumoniae, como las mayores productoras de estos compuestos (Tabla 3). Es importante destacar que especies de la familia Enterobacteriaceae no son consideradas miembros de la microbiota normal de la boca, posiblemente y entre otras razones, a que su capacidad de adhesión a receptores de la mucosa bucal se ve impedida o dificultada por la fibronectina. Esta proteína, puede desaparecer de la boca bien por un estado de inmunosupresión o por un aumento de actividad proteolítica de la saliva (37), situación esta última que se produce en la halitosis oral. No obstante, recientemente Goldberg y colaboradores, han aislado especies bacterias de esta familia en distintos grupos de pacientes y han observado una alta prevalencia en pacientes portadores de prótesis completa $48 \%$. Esto se podría explicar por la capacidad de adhesión de estas bacterias a la prótesis (38).

Las especies bacterianas con mayor capacidad de generar CVSs, son las siguientes: $F$. nucleatum, que tienen una gran capacidad de producir metionina, amonio y $\mathrm{CH}_{3} \mathrm{SH}$, es muy prevalentes en bolsas periodontales y está fuertemente relacionada con las enfermedad periodontales $(39,40)$, Treponema denticola, Porphyromonas gingivalis, Porphyromonas endodontalis, Prevotella intermedia y Bacteroides loeschii son capaces de producir una cantidad significativamente mayor de sulfuros que otras especies bacterianas $(16,17)$. Otras bacterias que se han aislado en las bolsas periodontales como Bacteroides forsythus, Centipeda periodontii, Eikenella corrodens y Fusobacterium periodonticum también tienen una gran capacidad para producir CVSs in vitro $(16,17,19)$.

Según los trabajos de McNamara, en ausencia de microorganismos el mal olor no se genera, observaron que era necesaria la presencia de microbiota para que se pudiera producir la degradación de la saliva. (41)

\section{FACTORES FISICOQUÍMICOS}

Las condiciones abióticas que determinarán el ambiente óptimo para la generación de CVSs por parte de las bacterias orales, están regidas por la saliva y los nichos ecológicos primarios, fundamentalmente el surco, la bolsa periodontal y el dorso de la lengua.

\section{Humedad}

El agua es un factor extremadamente favorable para el desarrollo microbiano, su disponibilidad en la cavidad oral se debe básicamente a la saliva.

La saliva está constituida por una mezcla compleja de secreciones de distintas glándulas salivales, junto con múltiples tipos bacterianos, células epiteliales descamadas, leucocitos destruidos y restos de alimentos.

El fenómeno de la halitosis se ha intentado reproducir en el laboratorio (41-43) mediante la incubación de la saliva bajo distintas condiciones. De dicha incubación, resulta la producción de compuestos volátiles y mal olor de la misma. Estos compuestos volátiles son producidos a partir de la hidrólisis bacteriana de los sustratos proteícos contenidos en la saliva $(3 ; 33)$.

\section{Potencial de Hidrógeno $(\mathrm{pH})$}

En la cavidad bucal la saliva va ha ser la responsable del mantenimiento del $\mathrm{pH}$, a través de su capacidad amortiguadora, en un rango comprendido entre 6,7 y 7,5 . Este $\mathrm{pH}$ puede ser sometido a distintas variaciones debido a la dieta y al metabolismo bacteriano principalmente (44). Estos cambios de $\mathrm{pH}$ se reflejan en el olor de la saliva, que en condiciones de salud no es desagradable. Sin embargo, se pueden producir cambios hacia un olor pútrido como consecuencia de cambios alcalinos en su pH. McNamara incubó saliva a pH 6.5 y a pH 7.5 durante 24 horas a $37^{\circ} \mathrm{C}$. A pH 7.5 el olor era fuerte y pútrido mientras que a $\mathrm{pH} 6.5$ no se emitía ningún olor (41). Kenney en otro trabajo, añadió glucosa a la saliva después de ser incubada, y esta transformaba su $\mathrm{pH}$ en ácido y resultaba de nuevo una solución no olorosa, lo que demuestra que un $\mathrm{pH}$ alcalino es necesario para la formación de los compuestos volátiles responsables de la halitosis (42).

\section{Potencial de óxido-reducción}

La reducción de la concentración de oxígeno en los distintos nichos ecológicos de la cavidad oral como superficies dentales, fisuras del dorso de la lengua y bolsas periodontales aumenta significativamente la producción de CVSs. Esta reducción de oxígeno ori- 
gina una disminución en el potencial de óxido-reducción $(45,46)$, lo que favorece el crecimiento de la microbiota anaerobia y la facultativa, responsables del metabolismo del componente $(17,33)$.

En los tejidos blandos y en la placa dental el nivel de óxigeno es muy bajo. En el interior de la placa bacteriana la tensión de óxigeno es de $0.32 \mathrm{mmHg}$, mientras que es de $12.5 \mathrm{mmHg}$ en la salida de la glándula parótida. La superficie de la placa dental presenta niveles similares de tensión de óxigeno a la salida de la glándula parótida, no obstante, a medida que engruesa la placa, esta tensión disminuye y es colonizada por bacterias gramnegativas anaeróbias que son las únicas capaces de sobrevivir en un medio ambiente reducido donde la tensión de oxigeno se aproxima a $0 \mathrm{mmHg}$. De ahí que la placa joven, esté principalmente constituida por bacterias que utilizan oxígeno $o$ pueden tolerarlo. Cuando se acumula placa, porque cesan las medidas de higiene, se produce una deplección de óxigeno que lleva al desarrollo de una placa anaeróbica gramnegativa periodontopatógena con una gran capacidad de producir CVSs (47).

\section{FACTORES NUTRICIONALES}

Los aminoácidos son los precursores de la producción de la halitosis oral (47). La proteolisis precede o es simultánea a la degradación de aminoácidos, pero no todos los aminoácidos son capaces, en su degradación, de producir CVSs. Los aminoácidos relacionados con la producción y liberación de CVSs son principalmente cisteina, metionina y cistina; tienen en común que en su estructura contienen sulfuro (47, 48).Tonzetich estudió distintos aminoácidos no sulfurados que se encontraban en la saliva, como serina y arginina. Observó que la degradación microbiana de estos aminoácidos no producía un incremento en la producción de CVSs (47).

Básicamente los aminoácidos sulfurados provienen de la saliva y/o la placa dental.

\section{Saliva}

La incubación del sobrenadante y del sedimento obtenido por centrifugado de la saliva demuestra que este sedimento puede producir mal olor, mientras que el sobrenadante no sería suficiente. El sedimento está constituido por bacterias y proteínas de células epiteliales descamadas (3).

La saliva es muy pobre en aminoácidos, esto determina que sea necesaria la hidrólisis previa de péptidos y otros sustratos protéicos contenidos en la saliva para que se provea de la necesaria fuente de ellos. La microbiota oral presente en la saliva es la encargada de realizar esta hidrólisis (44).

La saliva tiene un alto contenido protéico 200-300 $\mathrm{mg} / 100 \mathrm{~mL}$ son proteínas, $13-20 \mathrm{mg} / 100 \mathrm{~mL}$ es urea, y sólo $1 \mathrm{mg} / 100 \mathrm{~mL}$ es glucosa libre. Estos componentes protéicos son originados a partir de elementos celulares y no celulares procedentes de la mucosa y del fluido gingival (44). Ante condiciones óptimas de reducción de la concentración de oxígeno y ante un $\mathrm{pH}$ alcalino, se lleve a cabo el proceso de putrefacción de la saliva y, como consecuencia de ello, se emitan CVSs (48).

Las bacterias gramnegativas utilizan sustratos protéicos como fuente de energía principal, mientras que las bacterias grampositivas utilizan carbohidratos. En condiciones de insuficiente aporte de glucosa y carbohidratos, se producirá una desviación hacia una microbiota progresivamente gramnegativa, simplemente por un proceso de competitividad ecológica, lo que favorecerá la producción de halitosis.

\section{Placa dental}

La placa dental está constituida por bacterias dentro de una matriz abiótica formada por compuestos inorgánicos, agua, hidratos de carbono y proteínas, fundamentalmente glucoproteinas y proteínas salivales (50). La capa externa es la más rica en sustratos protéicos, por lo tanto, es la más importante para la producción de CVS. En contraste, la capa más interna está compuesta fundamentalmente de glucoproteínas salivales y paredes celulares de bacterias grampositivas muy pobres en contenido protéico. El estado de maduración de la placa condiciona la presencia de bacteria gramnegativas, que se multiplicarán con el incremento del grosor de la placa y con la disminución del potencial de óxido-reducción (33) que, en la patología periodontal, coincide con un aumento en la severidad de la gingivitis y de la periodontitis $(45,52)$.

\section{Dieta}

El valor de la dieta como fuente de nutrientes para la microbiota oral está limitado a los carbohidratos exógenos, siendo practicamente nulo el aporte protéico (44). Entre otras cuestiones, ésto se debe al breve tiempo de permanencia en boca de los alimentos. La microbiota relacionada con la halitosis es proteolítica y su principal fuente de nutrientes proviene de la degradación de proteínas celulares y glucoproteínas salivales. No obstante, la impactación de alimentos por falta de punto de contacto $o$ apiñamiento de dientes, y la retención de alimentos en los portadores de prótesis, puede representar un papel importante en algunos casos (1). 


\section{RELACIÓN ENTRE HALITOSIS Y ENFERMEDADES PERIODONTALES}

\section{Salud periodontal y halitosis oral}

Según Rosenberg en algunos pacientes la gingivitis y periodontitis puede ser suficiente para desencadenar un problema de halitosis, pero no es un requisito necesario para que ésta se produzca (32).

Distintos trabajos implican al dorso de la lengua como la fuente principal de producción CVSs tanto en situación de salud bucal como en la enfermedad (23, 40, 49, 52-56).

\section{Importancia del cubrimiento del dorso de la lengua}

El cubrimiento lingual está constituido por células epiteliales descamadas, células de la sangre y bacterias (Figura 6). Más de 100 especies bacterianas han

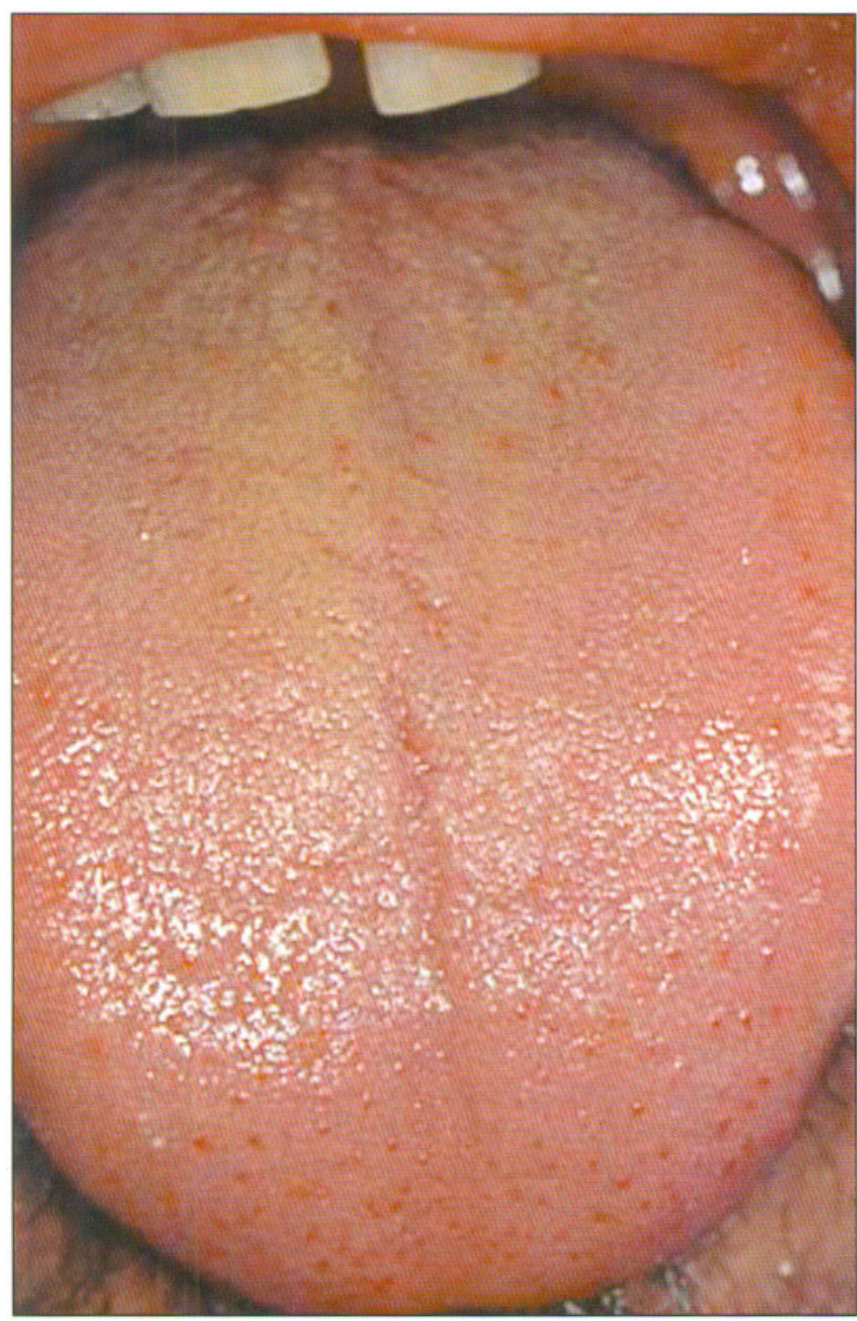

Fig. 6. El cubrimiento lingual está constituido por células epiteliales escamadas, células de la sangre y bacterias. sido identificadas en una única célula epitelial descamada del dorso de la lengua, mientras que, en células descamadas de otras áreas de la mucosa bucal, únicamente se han identificado 25 especies (52). La microbiota identificada sobre la superficie lingual es la misma que la existente en la placa subgingival (40).

El papel de las bacterias sobre la superficie lingual ha sido valorado in vitro y se ha observado que $P$. gingivalis, Treponema denticola, $B$. forsythus producen $\mathrm{H}_{2} \mathrm{~S}(16,17)$. Un test BANA positivo, que se basa en la capacidad de estas tres bacterias de hidrolizar el sustrato sintético benzoil-DL-arginina-2-naftalamida (BANA), realizado en muestras del dorso de la lengua y de localizaciones dentales se asocia fuertemente a la existencia de halitosis. Por el contrario, la realización de enjuagues con clorhexidina consigue una reducción significativa del mal olor (55).

Por otra parte, Kolovsky sólo observa una pobre asociación entre el test BANA positivo y concentración de CVSs (57).

Estas diferencias en las conclusiones respecto al test BANA y la halitosis, podrían explicarse por la baja especificidad del test diagnóstico que produce un elevado número de falsos positivos (58).

A pesar de la controversia suscitada respecto a la utilidad del test BANA para este fin, parece que hay más evidencias que apoyan la teoria de la responsabildad del cubrimiento lingual en la halitosis. Tonzetich ha sugerido que al eliminar el cubrimiento de la superficie lingual se reduce la producción de CVSs y que se obtienen periodos más largos de ausencia de halitosis cuando se limpia la lengua que cuando solo se cepillan los dientes o se realizan enjuagues bucales (53) (Figura 7).

En general, se observa que los pacientes con periodontitis crónica tienen una mayor cantidad de cubrimiento lingual que los pacientes en salud periodontal $(59,60)$.

Los trabajos de Bosy y colaboradores (49) han expuesto que algunos sujetos con patología periodontal exiben niveles elevados de halitosis, pero entre estos y los que tiene halitosis y están en salud periodontal no hay diferencias significativas en cuanto al grado de halitosis. De estos datos cabe inferir que la halitosis no está directamente asociada con la presencia de periodontitis, debido a que hay pacientes que no padecen periodontitis y sufren halitosis, y pacientes con periodontitis y sin halitosis. Por otra parte, el flujo salival es mínimo durante el sueño. Esto favorece el estancamiento del cubrimiento lingual y de placa dental, en el resto de mucosas y en el diente, y la puesta en marcha de los mecanismos de putre- 


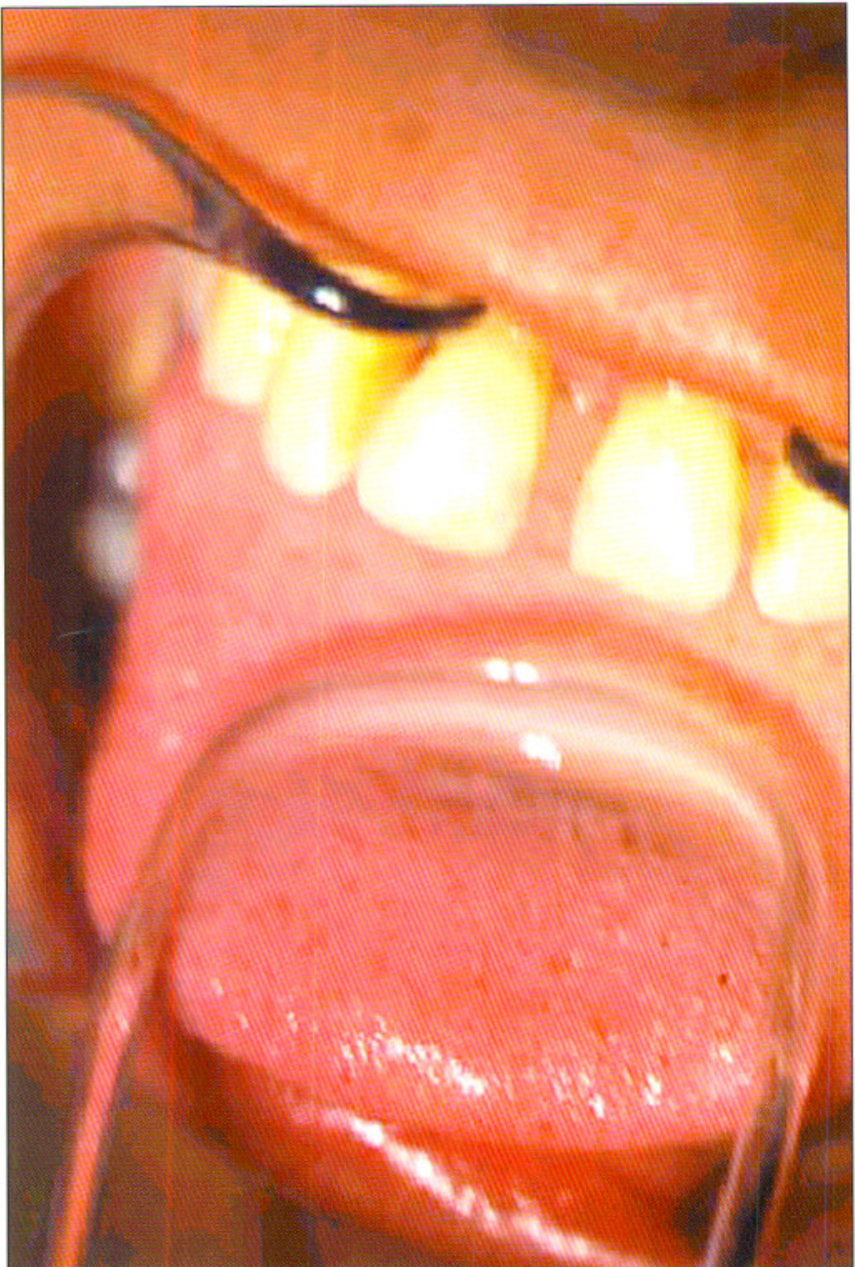

Fig. 7. Eliminación del cubrimiento lingual.

facción, lo que explica que por la mañana, tras el periodo de sueño, la halitosis sea más perceptible. En contraposición, durante los periodos de vigilia, el flujo salival aumenta y los mecanismos fisiológicos de autoclísis sobre las mucosas oral como el comer, beber o hablar, limitan el crecimiento de la microbiota oral y eliminan placa y restos de alimentos (49).

Es interesante resaltar que el cubrimiento lingual esta relacionado más fuertemente con la halitosis que con la severidad de la enfermedad periodontal. Esto se atribuye a la gran superficie de la lengua y a su estructura papilar que determina la retención de una gran cantidad de células epiteliales descamadas y leucocitos (Figura 8). Esta evidencia apoya la teoría de que el acúmulo bacteriano causa halitosis (54). De Boever (55), ha mostrado que cuando se recogen medidas de halitosis de toda la boca, no de áreas concretas como pueda ser el surco gingival, este mal olor está relacionado con el mal olor en una muestra de la lengua y con la cantidad de cubrimiento de la misma.

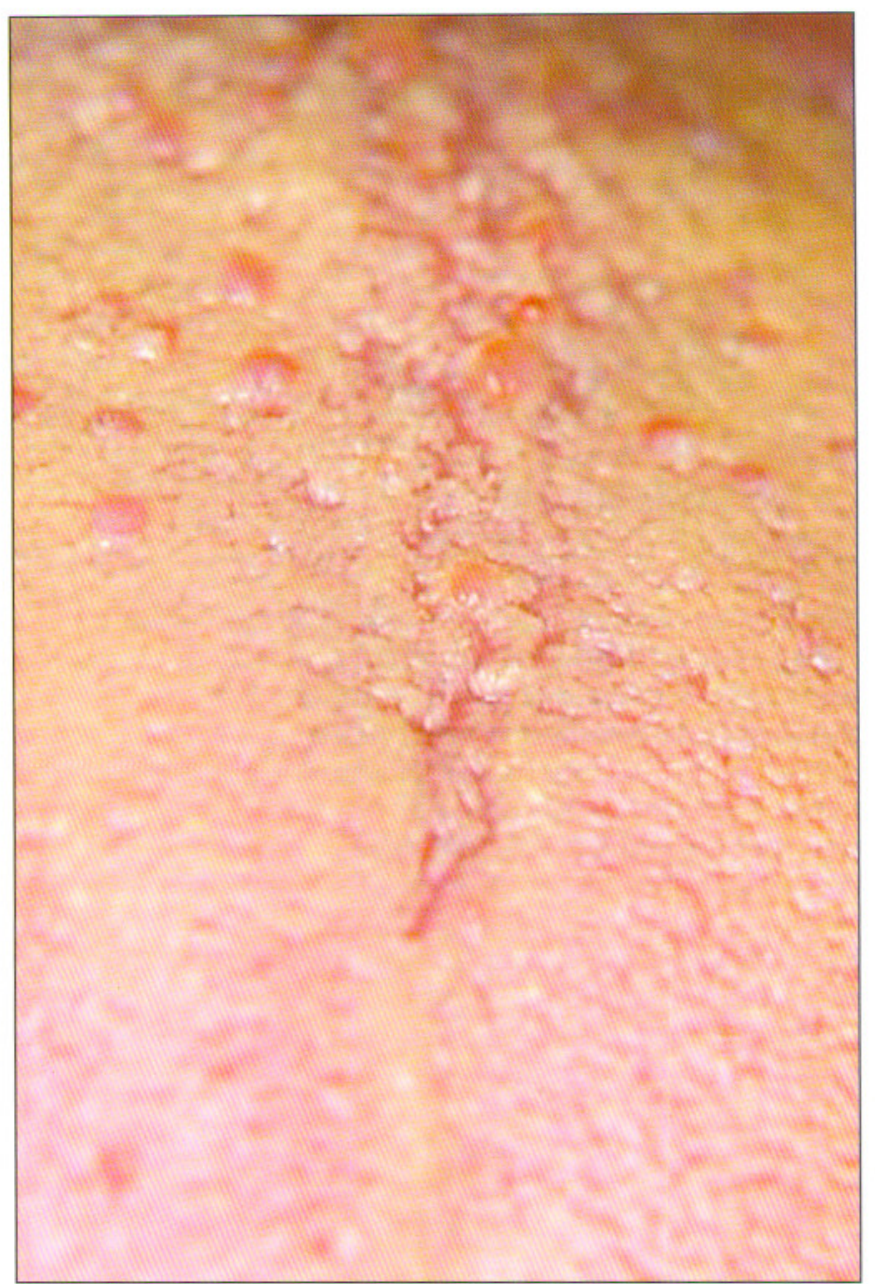

Fig. 8. Estructura papilar de la lengua.

En el estudio de Miyazaki (23) se observo en una muestra de 2672 individuos, que existía una elevada correlación entre la concentración de CVSs y el volumen de cubrimiento lingual en todos los grupos de edad. En este estudio, la correlación observada en el grupo de edad entre 45 y 64 años era mayor entre la concentración de VCSs y la progresión de la periodontitis que en el grupo de jóvenes. Basándonos en estos hallazgos parece que la fuente de mal olor en jóvenes esta más relacionada con el cubrimiento lingual que, en los adultos o mayores, con la enfermedad periodontal. No obstante, estas conclusiones hay que tomarlas con ciertas reservas, son estudios donde no se realizó un analisis multivariente de las variables y no se ha ajustado el efecto por la edad.

De todo lo anteriormente expuesto se puede inferir que la lengua es una fuente importante de halitosis.

Waller, diseñó un trabajo en el que a cuatro pacientes sin historia previa de halitosis les inocula $2 \mathrm{ml}$ de una disolución de cisteina en el área sublingual, en el ves- 


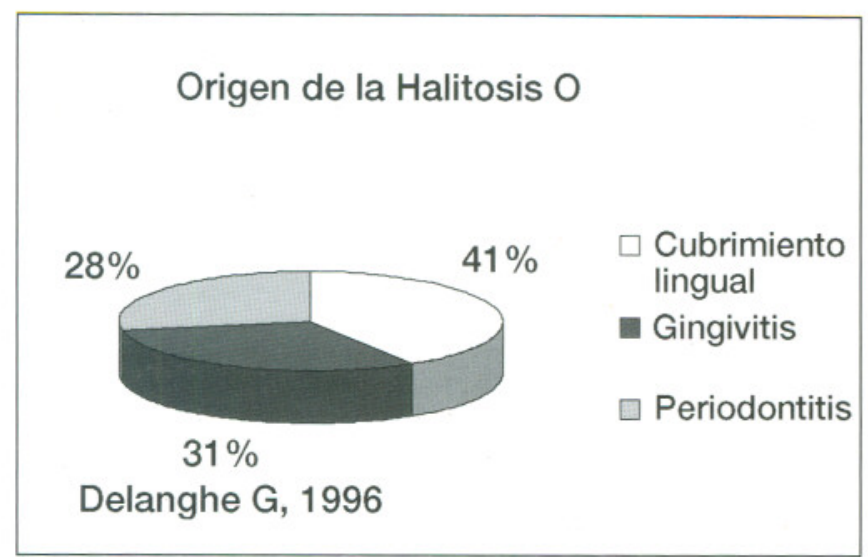

tíbulo y en el dorso de la lengua, respectivamente. Les recoge en un tubo $5 \mathrm{ml}$ de saliva e inocula $2 \mathrm{ml}$ de cisteina, que incuba durante 10 minutos a $37^{\circ} \mathrm{C}$ de temperatura. Los resultados sugieren que los valores más elevados en la concentración de CVSs, en todos los sujetos, se producen en el dorso de la lengua, mientras que los valores más bajos se dan en saliva, siendo similares en el vestíbulo y en el área sublingual (56).

La valoración organoléptica de la muestra del dorso de la lengua se ha asociado con niveles elevados de CVSs, por lo que se deduce que ésta es una fuente importante de halitosis

No obstante en los últimos 50 años distintas líneas de investigación han sugerido distintos grados de asociación entre las enfermedades periodontales y la halitosis.

Delanghe (28), en una muestra de 260 pacientes que referían halitosis, observó que la prevalencia de halitosis de origen oral era del $87 \%$. De este grupo en el $41 \%, 92$ pacientes, la causa de la halitosis fué el cubrimiento lingual. No debemos olvidar que en este mismo trabajo el 59\% de las halitosis eran consecuencia de una enfermedad periodontal (gingivitis $31 \% n=70$, periodontitis $28 \% n=63$ ) (Figura 9). En términos generales podríamos decir que cuando existe halitosis, salvo en una proporción de pacientes baja, el problema estará en la lengua o en el periodonto y, al menos, en uno de cada dos pacientes que refieran halitosis, la causa será periodontal.

\section{GINGIVITIS Y HALITOSIS}

La sangre, los leucocitos destruidos, las células descamadas y el fluido gingival, que se encuentran en los surcos gingivales suministran una cantidad significativa de sustratos protéicos sobre los que la microbiota periodontal actuará, hidrolizándolos y emitiendo una gran cantidad CVSs (61, 62). (Figura 10).

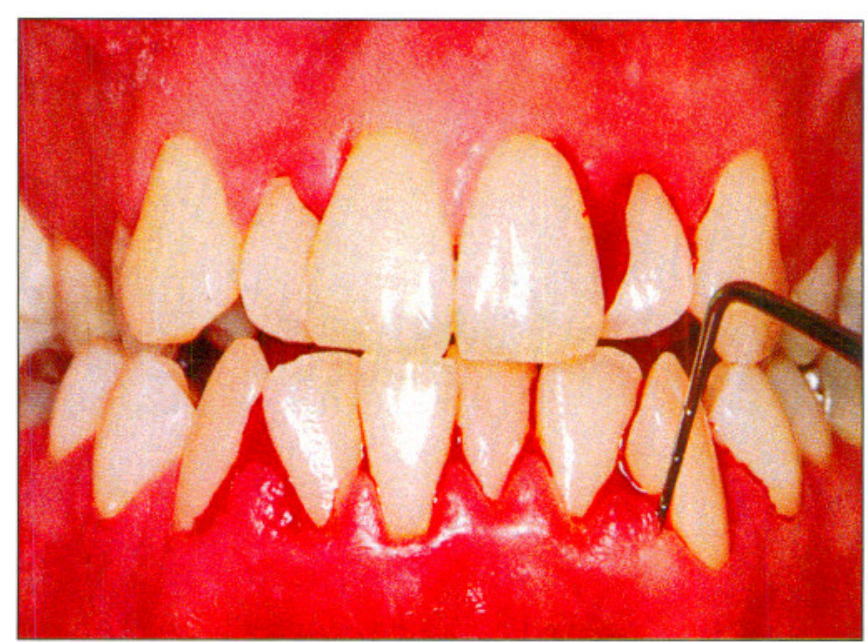

Fig. 10. Los surcos gingivales y las bolsas periodontales suministran una cantidad significativa de sustratos protéicos.

En gingivitis experimentales, la cantidad de CVSs espirado en el aire de la boca es significativamente más elevada en sujetos con gingivitis que en sujetos con salud periodontal. La producción de CVSs se incrementa en sujetos que desarrollan una gingivitis y disminuye cuando se vuelve a salud periodontal (63).

Otros estudios indican que las enfermedades periodontales, están relacionadas con la halitosis. Las condiciones de $\mathrm{pH}$, potencial de óxido-reducción, nutrientes y masa microbiana son óptimas en situación de periodontitis y gingivitis. Ante estas condiciones medio-ambientales óptimas se produce un incremento del metabolismo microbiano y un aumento de mal olor que se puede apreciar en la saliva (64).

\section{PERIODONTITIS Y HALITOSIS}

La periodontitis resulta de la destrucción de los tejidos de soporte del diente. Rizzo (65) ha encontrado que en las bolsas periodontales profundas la concentración de $\mathrm{H}_{2} \mathrm{~S}$ es muy elevada, relación confirmada posteriormente por Persson $(16,17)$ y Morita $(66,67)$.

Trabajos recientes han relacionado el incremento de sangrado al sondaje y la profundidad de la bolsa periodontal con incremento de $\mathrm{CH}_{3} \mathrm{SH}$ y $\mathrm{H}_{2} \mathrm{~S}$ en el interior de las bolsas periodontales (68). Estos hallazgos han sido corroborados por Morita que ha comunicado que los niveles de $\mathrm{H}_{2} \mathrm{~S}$ en el surco y en la bolsa periodontal, se correlacionan positivamente a medida que la profundidad de sondaje se incrementa (67). 
Los sujetos con bolsas periodontales mayores de 4 mm presentan unos niveles más elevados de CVSs que los sujetos con salud periodontal $(59,60)$. Estos niveles, además, se intensifican e incrementan con la severidad de la enfermedad periodontal (64). Por otra parte, hay evidencias de que la halitosis acelera la progresión de la enfermedad periodontal (4, 65). Esto podría explicarse por el cambio que se produce en la periodontitis hacia una microbiota más gramnegativa que produce $\mathrm{H}_{2} \mathrm{~S}$ y $\mathrm{CH}_{3} \mathrm{SH}$. $(16,17,69)$ lo que deriva en un aumento de la cantidad de productos metabólicos en el fluido crevicular (41), y en un incremento de la putrefacción de la saliva como consecuencia de la elevada concentración de células descamadas de la superficie dorsal de la lengua (4). La tendencia al sangrado en los tejidos periodontales provee de un sustrato ideal para la producción de mal olor. En presencia de gingivitis o periodontitis, las condiciones de $\mathrm{pH}$ alcalino y el potencial de óxido reducción son óptimas. Por otra parte, la carga bacteriana es elevada de ahí que los procesos de hidrólisis de los sustratos protéicos contenidos en la saliva y en el líquido crevicular son más rápidos y como consecuencia el olor de esa saliva es más desagradable que el de personas que no padecen estas patologías $(49,64)$.

Coil (68) utilizando cromatografía de gases estudió los CVS en el surco, en la bolsa peridontal y en la boca. Observó, que existen diferencias entre la calidad y la cantidad de CVSs en el aire de la boca y el aire crevicular. $\mathrm{El} \mathrm{H}_{2} \mathrm{~S}$ es el CVSs más predominante en el aire crevicular. $\mathrm{Y}$ el $\mathrm{CH}_{3} \mathrm{SH}$ es mas frecuente en el aire crevicular que $\mathrm{CH}_{3} \mathrm{SHCH}_{3}$. Las cantidades de $\mathrm{H}_{2} \mathrm{~S}$ y el $\mathrm{CH}_{3} \mathrm{SH}$ son más elevadas en bolsas profundas e inflamadas que en sitios poco profundos y no inflamados. Estos hallazgos son paralelos a los de Johnson (70).

Recientes trabajos de Quirynen sobre descontaminación periodontal (71), han sugerido que la halitosis oral puede estar asociada con el acúmulo de placa, gingivitis y periodontitis. Estas observaciones

- Efecto de CVSs sobre los tejidos periodontales

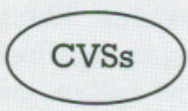

Aumento de Permeabilidad de los tejidos $+$

Facilitan la penetración de LPS

Clínica GINGIVITIS

Fig. 11. Los CVSs contribuyen a desarrollar gingivitis. se basan en que la desinfección de todos los nichos ecológicos orales reduce drásticamente los valores organolépticos del aire espirado de la cavidad oral.

Morita ha estudiado la correlación entre la severidad de la enfermedad periodontal y los niveles de $\mathrm{H}_{2} \mathrm{~S}$ en el surco periodontal utilizando un monitor portatil de sulfuro y ha encontrado que (66) los niveles de $\mathrm{H}_{2} \mathrm{~S}$ aumentan significativamente en sitios en los que se producen incrementos de perdida ósea radiológica. Por otra parte, los niveles de $\mathrm{H}_{2} \mathrm{~S}$ en el surco periodontal se correlacionan positivamente con el test BANA y sugieren que el nivel de $\mathrm{H}_{2} \mathrm{~S}$ en el surco periodontal es un potente indicador para detectar la severidad y la actividad de la enfermedad. En otro trabajo (67) se valoraba la asociación entre mal olor, factores demográficos, parámetros clínicos, niveles de $\mathrm{H}_{2} \mathrm{~S}$ sitio específico y test BANA positivo en dicha localización. Se concluyó que el mal olor está asociado con poca pérdida de hueso en la bolsa de estudio, pero no con gran pérdida de soporte. Estos estudios concuerdan con resultados anteriores de Condrey en 1999 (14), y recientes presentados en San Diego por Torrespayap (75).

\section{Efectos de CVSs en los tejidos periodontales}

El papel que juegan los CVSs en la patogenia de las enfermedades periodontales, ha sido avalado por la evidencia que aportan distintos trabajos. Estas moléculas volátiles pueden, de forma directa o indirecta, provocar la inflamación de los tejidos periodontales e inducir la destrucción de los mismos (Figura 11 y 12).

Estudios experimentales en animales han demostrado que en cultivos de mucosa sublingual no queratinizada expuestos $\mathrm{a} \mathrm{H}_{2} \mathrm{~S}$ y $\mathrm{CH}_{3} \mathrm{SH}$ se produce un incremento de la permeabilidad por encima del 75\% (76).

\section{- Efecto de CVSs sobre los tejidos periodontales} GINGIVITIS

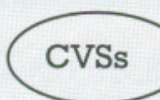

Incrementan la síntesis coleagenasa $+$ Alteración de sonización $+$

Alteración de la síntesis de colágeno<smiles>C=C</smiles>

Clínica PERIODONTITIS

Fig. 12. Los CVSs contribuyen a desarrollar Periodontitis. 
Existe evidencia de que los antígenos lipopolisacáridos de la pared bacteriana de las bacterias gramnegativas (LPS) inducen una inflamación gingival en algunos individuos, pero la exposición a estos antígenos no es suficiente para causar gingivitis en todos los pacientes (72). Parece que los LPS necesitan la prexistencia de una sustancia para penetrar en un epitelio sano. Es posible que los CVSs sean los encargados de facilitar la penetración de LPS, dando como resultado la inflamación del tejido (73). El resultado de estos hallazgos implican directamente a los CVSs con la gingivitis.

Los CVSs son potencialmente capaces de alterar la permeabilidad de los tejidos gingivales, inducir una respuesta inflamatoria y modular la respuesta de los fibroblastos. y $\mathrm{CH}_{3} \mathrm{SH}$ es capaz de alterar el metabolismo del colágeno reduciendo la síntesis e incrementando la degradación de proteínas $(70,77,78)$. Además, Johnson ha comunicado que el incremento de la concentración de CVSs incrementa la solubilidad del colágeno al hacerlo más susceptible a la degradación enzimática, con lo que se incrementa la destrucción del mismo (70).

Estas moléculas volátiles contribuyen al incremento de la síntesis de colagenasa lo que puede incrementar la destrucción tisular (79).

Por otra parte, aunque los leucocitos polimorfonucleares poseen capacidad bactericida en presencia de sulfuro, estas moléculas volátiles afectan a la opsonización inactivando el fragmento C3 del sistema complemento y como resultado afectan a la capacidad defensiva del hospedador (80).

El $\mathrm{CH}_{3} \mathrm{SH}$ y $\mathrm{H}_{2} \mathrm{~S}$ interaccionan con grupos tioles de las proteínas y provocan una alteración de la función normal del colágeno tipo I, siendo más nocivo $\mathrm{CH}_{3} \mathrm{SH}$. Distintos trabajos han mostrado que la proporción $\mathrm{CH}_{3} \mathrm{SH} / \mathrm{H}_{2} \mathrm{~S}$ se incrementa con la severidad de las enfermedades periodontales $(59,60,68)$.

CVSs como predictores de enfermedad periodontal.

Distintos autores $(74,75,81,82)$ apoyan la hipótesis de que la concentración de CVSs en las bolsas periodontales podría ser utilizada como predictor sitio específico de las periodontitis. Proponen que los CVSs, fundamentalmente, $\mathrm{H}_{2} \mathrm{~S}$ y $\mathrm{CH}_{3} \mathrm{SH}$ producido por las bacterias periodontopatógenas anaerobias gramnegativas son unos predictores fiables de la actividad y de la severidad de la enfermedad periodontal. Su hipótesis es que estas moléculas son un indicador indirecto de la presencia de estas bacterias periodontopatógenas. Esto permitiría detectar sitios activos de enfermedad, cuantificar la respuesta a la terapéutica y predecir sitios futuros de actividad de enfermedad.

\section{CONCLUSIÓN Y RELEVANCIA CLÍNICA}

De la exposición anterior podemos extraer implicaciones clínicas muy relevantes.

En primer lugar, y a la luz de la evidencia disponible, es posible que la prevalencia de la halitosis este comprendida en un rango entre 6 y el $24 \%$ de la población general y su interés se remonta a cientos de años.

En segundo lugar, es probable que en uno de cada dos pacientes que refieran halitosis el origen sea periodontal. Cuando la halitosis se produce como consecuencia de la patología periodontal, mediante un diagnóstico y tratamiento adecuados, este signo clínico debe desaparecer.

En tercer lugar, no debemos olvidar que, indistintamente de que la causa de la halitosis oral sea debida a una enfermedad periodontal o no, el tratamiento de la patología que provoca el problema va a permitir actuar sobre algunos factores implicados directamente en la patogenia de las enfermedades periodontales.

Por último, se está trabajando en el papel que los CVSs podrían presentar como predictores sitio específico de actividad de enfermedad periodontal. No obstante, sería deseable conocer la reproductibilidad de la prueba así como su validez diagnóstica antes de que fuera utilizada por el clínico.

\section{ABSTRACT}

Bad breath, oral malodour and halitosis they are terms used describe unpleasant odour out from the oral cavity, independently from the source where the odorous can be oral no oral. The majority of bad breath originates within the mouth. They have been attributed mainly attributed to volatile sulfur compounds (VSC) such as hydrogen sulfide, methyl mercaptan and dimethyl sulfide. The primary cause are bacteria gram-negative bacteria that are similar to the causing periodontal diseases. These bacterias produce the VSC by metabolizing epithelial cells, leukocytes, etc., mainly located in saliva, dental plaque. Tongue surface is composed of desquamated epithelial cells and bacterias, suggestig that it has the proteolytic and putrefactive capacity to produce VSC.

The aim of this review article: (1) to analyze the evidence the importance of the bad breath in the current context, (2) to study the data your etiology and (3) to value the association between the periodontal diseases and the halitosis of oral origin. 


\section{KEY WORDS}

Bad breath, sulfur volatile compounds, anaerobic bacteria, periodontal disease, halitosis/etiology, tongue coating.

\section{CORRESPONDENCIA}

Manuel Menéndez Collar

Clínica Menéndez Collar

Avenida Gran Capitán 44, $1^{\circ} 2$

Córdoba

Teléfono: 957496689

Fax: 957496690

Correo electrónico:

clinica@clinicamenendezcollar.com

\section{BIBLIOGRAFÍA}

1. Rosenberg M. Clinical assessment of bad breath: current concepts. JADA 1996; 127: 475-82.

2. Van Steenberghe D. Breath malodor. Current Opinion in Periodontology 1997; 4: 137-43.

3. Tonzetich J. Direct gas chromatographic analysis of sulphur compounds in mouth air in man. Arch Oral Biol 1971; 16: 587-7.

4. Tonzetich J. Production and origin of oral malodor: a review of mechanisms and methods of analysis. Periodontol 1977; 48: 13-20.

5. Rosenberg M., Septon I., Eli I., Bar-Ness R, Gelernter I, Brenner S, Gabbay J.: Halitosis measurement by an industrial sulfide monitor. J Periodontol 1991; 62: 487-9.

6. Rosenberg M, Kulkarni GV, Bosy A, McCulloch CAG. Reproducibility and sensitivity of oral malodour measurements with a portable monitor sulphide monitor. J Dent Res 1991; 70: 1436-40.

7. Schmidt NF, Missau SR, Tarbet WJ, Cooper AD. The correlation between organoleptic mouth-odour ratings and levels of volatile sulfur compounds. Oral Surg Oral Med Oral Pathol 1978; 45: 560-7.

8. Shigeta Y. Malodor and organoleptic examination. En: Introduction to Organoleptic Examinations. Tokyo: The Japanese Bureau of environmental Health Publications; 1980: 132-3.

9. Shimura M, Watanabe S, Iwakura M, et al. Correlation between measurements using a new halitosis monitor and organoleptic assessment. J Periodontol 1997; 68: 1182-5.

10. Iwakura M, Yasuno Y, Shimura M, Sakamoto S. Clinical characteristics of halitosis: differences in two patient groups with primary and secondary complaints of halitosis. J Dent Res 1994; 73: 1568-74.
11. Solis-Gaffar M, Niles HP, Rainieri WC and Kestenbaum RC. Instrumental evaluation of mouth odour in a human clinical study. J Dent Res 1975; 18: 351-7.

12. Tangerman A, Meuwese-Arends M, Van Tongeren JHM. New methods for the release of volatile sulfur compounds from human serums: its determination by Tenax trapping and gas chromatography and its application in liver diseases. J Lab Clin Med 1985; 106: 175-82.

13. Tangerman A, Meuwese-Arends M, Van Tongeren JHM. A new sensitive assay for measuring volatile sulphur compounds in human breath by Tenax trapping and gas chromatography and its application in liver cirrhosis. Clinica Chimica Acta 1983; 130: 103-10.

14. Clauss B, Geypens B, Rutgeerts P, Ghyselen J, Hoshi K, Van Steenberghe D. Closed-loop trapping and highresolution gas chromatography-ion trap detection. En: Bad Breath: A multidisciplinary Approach. Leuven: D Van Steenberghe and M Rosenberg Editors 1996; 2: 1529.

15. Pianotti R, Lachette S, Dillis S. Desulfuration of cysteine and methionine by Fusobacterium nucleatum. J Dent Res 1986; 65: 913-7.

16. Persson S, Claesson R, CarlssonJ. The capacity of subgingival species to produce volatile sulphur compounds in human serum. Oral Microbiol Immunol 1989; 4: 169-72.

17. Persson S, Edlund MB, Claesson R, Carlsson J. The formation of hydrogen sulphide and methylmercaptan by oral bacteria. Oral Microbiol lmmunol 1990; 5: 195-201.

18. De Boever E, De Uzeda M, Loesche WJ. Relationship between volatile sulfur compounds, BANA-hydrolyzing bacteria and gingival health in patients with and without complaints of oral malodor. J Clin Dent 1994; 4: 114-9.

19. Goldberg S, Kozlovsky A, Gordon D, Gelemter I, Sintov A, Rosenberg M. Cadaverine as a putative component of oral malodor. J Dent Res 1994; 73: 1168-72.

20. Newman MG. The role of periodontitis in oral malodour En: Bad Breath: A multidisciplinary Approach. Leuven: D Van Steenberghe and M Rosenberg Ed. 1996: 3-14.

21. Maita E. A simple detector for oral malodour. En: Bad Breath: A multidisciplinary Approach. Leuven: D Van Steenberghe and M Rosenberg Editors 1996; 19: 209-16.

22. Solis-Gaffar M, Rustogi K, Gaffar A Hydrogen sulphide production from gingival crevicular fluid. J Periodontol 1980; 51: 603-6.

23. Miyazaki H, Sakao S, Katoh Y, Takehara T. Correlation between volatile sulphur compounds and certain oral health measurements in the general population. J Periodontol 1995; 66: 679-84.

24. Tessier y Kulkarni 1991. Bad breath:etiology, diagnosis and treatment. Oral Healt 1991; 81: 19-22.

25. Yaegaki F, Sanada K, Mirot F. L'halitose d'origine buccale: etiologie, diagnostic et traitement. J Parodontol 1992; 12: $27-33$ 
26. Yaegaki K, Coil JM. Examination, classifcation, and treatment of halitosis; clinical prespectives. J Can Dent Assoc. 2000; 66: 257-61.

27. Sanz M, Roldán S, Herrera D. Fundamentals of breath malodour. J Comtemp Dent Pract 2001; (2) 4: 1-17.

28. Delanghe G, Ghyselen J, Feenstra L, Van Steenberghe D. Experiences of a Belgian Multidisciplinary Breath Odour Clinic. En: Bad Breath: A multidisciplinary Approach. Leuven: D Van Steenberghe and M Rosenberg Editors 1996; 18: 199-208.

29. Tomás I, Limeres J, Diz P, Fernández J, Vázquez E. Etilogía extraoral de la halitosis. Medicina Oral 2001; 6: 40-7

30. Tiomny E, Arber N, Moshkowitz M, Peled Y, GilatT. Halitosis and Helicobacter pylori. J Clin Gastroenterol 1992; 15: 236-7.

31. Norfleet RG: Heicobacter halitosis. J Clin Gastroenterol 1993; 16: 274.

32. Rosenberg M. Intoduction. En: Bad Breath: Research perpestives. Ramat Aviv: Ramot Publishing- Tel Aviv University,: M. Rosenberg Ed. 1995: 1-12.

33. Kleinberg I, Westbay G. Oral malodor. Critical Rev Oral Biol 1990; 1: 247-59.

34. Willis CL; Gibson GR, Holt J, Allison C. Negative correlation between oral malodour and numbers and activities of sulphate-reducing bacteria in the human mouth. Arch Oral Biol 1999; 44: 665-70.

35. Bolúmar F, Delgado M. Diseños de investigaciones en ciencias de la salud. Barcelona Signo. 2000.

36. Richter VJ, Tonzetich J. The application of instrumental technique for the evaluation of odoriferous volatiles from saliva and breath. Arch Oral Biol 1964; 9: 47-53.

37. Mirelis B, Coll P, Sánchez F. Diversidad bacteriana. Principales bacterias de interés en patología humana. En: Microbiología oral. Madrid. Liébana J. Editor, 1995: 195-207.

38. Goldberg S, Cardash H, Browining III H, Sahly H, Rosenberg M. Insolation of Enterobacteriaceae from the mouth and potential association with malodor. J Dent Res 1997; 76: 1770-5.

39. Gordon DF: Gibbons RJ. Studies of the predominant cultivable micro-organisms from the human tongue. Arch Oral Biol 1966; 11: 627-32.

40. Van Winkelhof, 1986 Van Winkelhoff $A J$, Vam der Velden U, Winkel EG, De Graff J. Black-pigmented bacteroides and motile organisms on oral mucosal surfaces in individuals with and without periodontal breakdown. J Periodont Res 1986; 21: 434-9.

41. McNamara TF, Alexander JF, Lee M. The role of microorganisms in the production of oral malodour. Oral Surg 1972; 34: 41-8.

42. Kenney EB, Ash MM. Oxidation-reduction potential of developing plaque, periodontal pockets and gingival sulci. J Periodontol 1969; 40: 630-3.

43. El-Maaytah MA, Hartley MG, Greenman J, Porter SR, Scully CM. Relationship of the salivary incubation test with oral malodour levels. En: Bad Breath: A multidisciplinary Approach. Leuven: D Van Steenberghe and M Rosenberg Editors 1996; 11: 135-42.

44. Liébana J, Castillo A $\mathrm{M}^{\mathrm{a}}$, García-Mendoza A. Determinantes ecológicos orales. En: Microbiología oral. Madrid. Liébana J. Editor, 1995: 409-27.

45. Kleinberg I. Regulation on the acid-base metabolism of the dentogingival plaque and its relation to dental caries and periodontal disease. Int Dent J 1970; 10: 451-65.

46. Globerman DY, Kelinberg I. Intra-oral PO2 and its relation to bacterial accumulation on the oral tissues. En: Saliva and dental caries Kleinberg I, Ellison SA, Mandel ID, editors New York and Washington Information Retrieval 1979: 275-91.

47. Tonzetich J, Carpenter PAW. Production of volatile sulphur compounds from cysteine, cistine and methionine by human dental plaque. Arch Oral Biol 1971; 16: 599607.

48. Sanz M, Zabalegui I, González JL. Halitosis oral. ROC 1996; 1: 97-104.

49. Bosy A, Kulkarni GV; Rosenberg M, McCuloch CAG. Relationship of oral malodour to periodontitis: evidence of independence in discrete subpopulations. J Periodontol 1994; 65: 37-46.

50. Liébana J, Baca P. Microbiología de las placas dentales. En: Microbiología oral. Madrid. Liébana J. Editor, 1995: 429-45.

51. Singer DL, Kleinberg I. Quantitative assessment of urea, glucose an damping changes in human dental plaque and saliva following rinsing with urea and glucose. Arch Oral Biol 1983; 28: 923-9.

52. Yaegaki F, Sanada K. Volatile sulfur compounds in mouth air from clinically healthy participants and patients with periodontal disease. J Periodont Res 1992; 27: 233-8.

53. Tonzetich J, Ng S. K. Reduction of maoldour by oral cleasing procedures. Oral Surg Oral Med Oral Pathol. 1976; 42: 172-81.

54. Loesche WJ, De Boever E H. Strategies to indentify the main microbial contributors to oral malodor. En: Bad Breath: Reserarch perpestives. Ramat Aviv: Ramot Publishing- Tel Aviv University,: M. Rosenberg Ed. 1995: 41-69.

55. De Boever E, Loesche WJ. Assessing the contribution of anaerobic microflora of the tongue to oral malodour . JADA 1995; 126: 1384-93.

56. Waller S. M. On the trasnformation of sulfur-containing amino acids and peptides to volatile sulfur compounds (VCS) in the human mouth. Eur J Oral Sci. 1997; 105: 5347 . 
57. Kozlovsky A, Gordon D, Gelernter I, Loesche WJ, Rosenberg M. Correlation between the BANA test and oral malodor parameters. J Dent Res 1994; 73: 1036-42.

58. Loesche W J, Kazor C E, Taylor G W. The optimization of the BANA test as a screening instrument for gingivitis among subjets seeking dental treatment. J Clinical Periodontol 1997: 718-26.

59. Yaegaki K, Sanada K. Biochemical and clinical factors influencing oral malodor in periodontal patients. J Periodontol 1992; 63:783-9.

60. Yaegaki K, Sanada K. Volatile sulfur compounds in mouth air from clinically healthy subjects and patients with periodontal disease. J Periodont Res 1992; 27: 233-8.

61. Golub LM, Borden SM, Kleinberg I. Urea content of gingival crevicular fluid and its relation to periodontal disease in humans. J Periodont Res 1971; 6:243-51.

62. Dawes C. Physiological factors affecting salivary flow rate, oral sugar clearance, and the sensation of dry mouth in man. J Dent Res 1987; 66: 648-53.

63. Ko Y. H., Kim Y. J., Chung H. J. Methyl mercaptan concentration during experimental gingivitis in man. J Dent Res. 1996; 75: 195.

64. Kostelc J C, Petri G, Zelson P R, Brauner L, Baehni P. Oral odors in eraly experimental gingivitis. J Periodont Res 1984; 19: 303-12.

65. Rizzo A. The possible role of hydrogen sulphide in human periodontal disease. I. Hydrogen sulphide production in periodontal pockets. Periodontics 1967; 5: 233-6.

66. Morita M, Wang M L. Relationship of sulcular sulphide level and oral malodor in subjects with periodontal disease. J Periodontol 2001; 72:74-8.

67. Morita M, Wang M L. Relationship of sulcular sulphide level to severity of periodontal disease and BANA test. J Periodontol 2001; 72: 79-84.

68. Coil J.M. Characterization of volatile sulphur compounds production at individual crevicular sites. En: Bad Breath: A multidisciplinary Approach. Leuven: D Van Steenberghe and M Rosenberg Editors 1996; 1: 29-34.

69. Persson S. Hydrogen sulphide and methylmercaptan in periodontal pokets. Oral Microbiol lmmunol 1992; 7: 3789.
70. Johnson P.W., Yaegaki K, Tonzetich J. Effect of volatile thiol compounds on protein metabolism by human gingival fibroblats. J Periodont Res 1992; 27: 553-61.

71. Quirynen M, Mongardini C, Steenberghe D. The effect of a 1-Stage full-mouth disinfection on oral malodor and microbial colonization of th tongue in periodontitis patients. A pilot study. J Periodontol 1998; 69: 374-82.

72. Offenbacher S. Periodontal diseasses: pathogenesis. Ann Periodontol 1996; 1: 821-78.

73. Ratcliff P A, Johnson P W. The relationship between oral malodor, gingivitis, and periodontitis: a rewiew. J Periodontol 1999; 70: 485-9.

74. Condrey G. Evaluation of sulfide by-products in periodontal therapy. (Thesis for Degree of Master of Science, University of Texas Health Science Center at Houston, Dental Branch; 1999)

75. Torresyap G, Uzel NG, Haffajee AD, Socransky SS. Relations between periodontal poket sulfide levels and subgingival species. (Comunicación personal); IADR/AADR/CADR/ 80 th General Session (March 9, 2002) San Diego, EEUU.

76. $74 \mathrm{Ng} \mathrm{W}$, Tonzetich J. Effect of hidrogen sulfide and methyl mercaptan on the permeability of mucosa oral. J Dent Res 1984; 63: 994-7.

77. Johnson P. W., Ng W, Tonzetich J. Modulation of human gingival fibroblast cell metabolism by methyl mercaptan. J Periodont Res 1992; 27: 476-83.

78. Johnson P. W., Ng W, Tonzetich J. Effect of methyl mercaptan on synthesis and degradation of collagen. J Periodont Res 1996; 31: 323-9.

79. Ratkay L G, Waterfield J D, Tonzetich J. Stimulation of enzyme and cytokine production by methyl mercaptan in human gingival fibroblast and monocyte cell cultures. Arch Oral Biol 1995; 40: 337-44.

80. Claesson R, granlund-Edstedt M, Persson S, Carlsson J. Activity of polymorphonuclear leukocytes in the presence of sulfide. Infec Inmun 1989; 57: 2776-81.

81. Morita M, Wang H L. Asssociatión between oral malodor and adult periodontitis:a review. J Clin Periodontol 2001; 28: 813-9.

82. Fine D H, Mandel I D. Indicators of periodontal disease activity: a evaluation. J Clin Periodontol 1986; 13: 533-46. 